\title{
Heterogeneity in the Effects of Group Lending in Microfinance-The Case of Mongolia
}

\author{
Takaharu Ishii \\ Dept. of Management, Business Breakthrough University \\ 3 Nibancho, Chiyoda-ku, Tokyo, Japan \\ Tel: +81-90-8919-4012Ｅ-mail: takaharuishii7@yahoo.co.jp
}

Received: December 29, 2021 Accepted: January 27, 2022 Published: February 7, 2022

doi: $10.52941 /$ jad.v8i1.25 URL: https://doi.org/10.52941/jad.v8i1.25 


\section{Abstract}

This study examines the heterogeneity of the effects of the joint and several liability systems of microfinance in Mongolia. The heterogeneity was examined from three perspectives: consumption, repayment rate, and income.

In terms of business income and business expenditure, the older the household, the greater the number of loans, and the more private businesses the household owns, the greater the business expenditure. For household consumption, there is no difference between group and individual lending except in the number of private businesses, but when we restrict the analysis to food consumption, group lending increases food consumption more for households with more than one borrower and borrowers with longer borrowing periods. While more variable heterogeneity was found for the whole sample, only age and borrowing duration were found to affect household income across different types of microfinance for the poorest households with below median household income. The results of this study suggest that even if there was no significant difference in each attribute between the treatment and control groups, joint and several liabilities may or may not be effective depending on the level of the attribute. To maximize the effect of a simple measure, it is important to understand the factors that affect heterogeneity and the effective level of the heterogeneity. Even if a measure is not effective, it may become effective if the level of the attribute changes.

Keywords: Group lending, microfinance, causal forest, Mongolia, heterogeneity, CATE

\section{Introduction}

The purpose of this study is to examine the effect of heterogeneity on joint and several liabilities in microfinance. In recent years, there has been a growing trend to conduct rigorous impact evaluations using RCT and other methods to capture the heterogeneity in the results to optimize targeting and cost-benefit. In the field of microfinance, the effects of group lending with joint and several liability schemes have been examined in several studies around the world, but no clear conclusions have been reached. While previous studies have suggested that the relationship between the magnitude of the advantages and disadvantages of introducing a joint and several liability systems is important, this study provides new insights into the effects of a joint and several liability systems in microfinance by clarifying the factors that affect the relationship between the magnitude of the advantages and disadvantages through an examination of heterogeneity. This study provides new insights into the effects of joint and several liability systems in microfinance. By assuming that the reason for the lack of clarity in the effects of solidarity responsibility schemes around the world is due not only to attributes but also to the level of attributes, we believe that we can predict the effects in advance by not only balancing the control and control groups through RCT but also by clarifying the level of both groups even if they are balanced.

\section{Previous Research on Joint and Several Liabilities of MFs}

Prior studies have not drawn clear conclusions about the effects of MF joint and several 
liabilities on risk taking and investment behavior. Group lending creates a moral hazard when members expect that they will be bailed out, and borrowers have incentives to shift to riskier projects. On the other hand, joint and several liabilities reinforces social pressure among members and increases the incentive for members to repay since all members are punished in case of default. As a result, it reduces the risk among members and may increase the repayment rate. Moral hazard due to risk-taking has been noted when borrowers know the investment strategies of members and when borrowers can self-select the projects in which they invest (Giné et al. (2010)). Fischer (2013) found that when information about each other's projects is restricted, group lending increase the incentives for free-riding; Giné and Karlan (2014) found a relationship between joint and several liabilities and repayment rates; Carpenaet al. (2013) showed that switching from individual to joint and several liabilities significantly increases repayment rates; and Fischer (2013) found that group lending is more likely to result in a higher repayment rate.

\subsection{Previous Studies on Conditional Average Intervention Effect (CATE)}

Athey and Imbens (2019) applied a tree-based method to causal inference, and Wager and Athey (2018) developed the method as Causal Forest and found that the CATE predicted by the method have congruence and asymptotic normality under certain conditions. They also predict CATE in areas such as poverty and labor studies, taxation, and energy conservation, and examine the characteristics of their distributions and what attributes explain their heterogeneity (Meller 2020, Carter, Tjernstrom and Toledo 2019, De Neve et al. 2019, Farbmacher, Kogel and Spindler 2019, Hoffman and Mast 2019, O'Neil and Weeks 2018). The usefulness of implementing targets for intervention through CATE has also been suggested. (Bertrand et al. 2017, Davis \& Heller, 2017; Knittel \& Stolper, 2019). The Causal Forest (CF) uses the Honesty method to further divide the training data into two parts, one of which is used to select the model's split points, and the other is used to select the model's split points. The expected value of the MSE, the EMSE estimator, is obtained by creating multiple causal trees that reward splits that lead to strong heterogeneity in the intervention effect and penalize splits that increase the variance of the estimator within a leaf and then integrating the results. Athey, Tibshirani and Wager (2019) used the generalized method of moments as a generalized random forest to estimate the effect of the intervention. The grf package for $\mathrm{R}$ is available (Tibshirani et al. 2020).

Carter, Tjernstrom and Toledo (2019) examined the heterogeneity of the effects of income enhancement programs on small farmers in Nicaragua and reported that the effects were larger for farmers with lower initial land assets, technical efficiency and education levels, and less farming experience.

De Neve et al. (2019) examined the heterogeneity of the effects of nudges on tax payment rates and found that simplifying the content of documents related to tax payment procedures alone had little effect on the elderly, that deterrent messages specifying penalties for delays in paying taxes and tax increases were more effective for the young, and that households with children For 
households with children, simplification is more effective.

Farbmacher, Kogel and Spindler (2019) examined poverty status and cognitive ability, and Hoffman and Mast (2019) examined the effect of government spending on the incidence of crime and estimate heterogeneity of the effect by region. They show that crime rates are suppressed in areas with low income and low employment growth; O'Neil and Weeks (2018) examined the effect of hourly electricity rates on electricity saving behavior and find that the intervention effect is larger for younger and more educated households with larger electricity use. Miller (2020) examined the effect of individual catch quota schemes on fishery collapse and found that policy effects vary through time and that the intervention effects of quota schemes are not only heterogeneous across fisheries but also heterogeneous with respect to the passage of time. Bertrand et al. (2017) examined the effect of temporary employment on employment status in response to public works implemented in Côte d'Ivoire and found that the heterogeneity of public works to increase income is large and that targeting is based on the intervention effect of heterogeneity can be cost-effective.

Chernozhukov et al. (2018) proposed a method called BLP, which assumes that the heterogeneity of the intervention effects is linear, and estimates the degree to which actual and predicted outcomes are correlated. It can be verified by test_calibration in $\mathrm{R}$ grf.

Zhenyu and Totte (2020) used Uber's data to examine whether it is cost-effective to hit which customers with which campaigns in which channels, and whether strategically personalizing the design and content in the app can increase the effectiveness. Using Uplift modeling, a modeling technique aimed at maximizing the effect of interventions, we showed that the improved models of X-lerner and R-learner were the most effective. We used the AUUC index, which shows how effective the intervention is for what proportion of the population compared to the baseline, to verify the individual causal effects, and used a method called Direct Ranking Model (DRM) to compare it with Causal Forest and R-Learner, and DRM was found to have the highest retention effect.

\section{Data}

This study uses data from Attanasio et al. $(2015,2018)$ to examine the heterogeneity of intervention effects. We randomly assigned from 1,148 poor households in Mongolia to examine the effects of group and individual borrowing among 40 rural poor. A follow-up survey was conducted 19 months after the baseline survey. Group borrowing is based on joint and several liabilities, where the entire group of borrowers is responsible for repayment. If one or more members do not repay and other members do not cover, all members will be denied further loans. The members act as guarantors who screen and monitor each other, thereby reducing the problem of asymmetric information between the MFI and the borrower's agency. Joint and several liabilities lending involves frequent information-sharing meetings among members to prevent default and increase the probability of repayment through strong social pressure. Although the borrowing in this study was intended to finance business, about half of the loans were used for 
household consumption. Group loan borrowing was also used for food consumption, especially milk, bread, and non-alcoholic beverages. Borrowers were limited to women who had requested to borrow at the initial information sessions held by the MFIs in each village and were not informed at the time of borrowing whether the loan would be an individual or group loan. From the baseline survey to the 19-month follow-up survey, the attrition rate increased by $16 \%$, but there was no significant difference between the group lending groups. As a nomadic people, Mongolians accumulate social capital outside the family, and collective self-help groups (Nukhurlul) exist. The fact that these groups operate as informal savings and credit unions, and have historically been similar to group lending, may have an impact on the current group lending practices of MFIs in Mongolia. As for commercial bank lenders, Xac Bank, a micro-lender, lends to both men and women, while Khan Bank, which has existed since the communist era, has lent to men. Khan Bank has had little incentive to diversify its lending and has lent to wealthy nomads using animals as collateral.

Both individual and group loans in this study were primarily for small-scale entrepreneurial activities and business creation, with repayment periods ranging from as little as a few weeks to as long as six months or more. The maturity of the group loans was approximately three years, with interest rates averaging 2 percent.

Xac Bank terminated lending to the group if the group did not repay the loan in full. The maximum size of the first loan to a group member is MNT500,000 (\$435). Members had to agree on who would receive the loan and how much, and if the MFI considered a particular borrower's project to be too risky, it would stop providing loans only to that particular borrower. In some cases, MFIs stopped lending to the entire group if they considered several group members to be at high risk. Members could pledge assets as collateral instead of compulsory savings, and while Xac Bank encouraged savings, 46\% of group members pledged their own houses, pao, and household goods as collateral. The group leader is responsible for monitoring and collecting repayments and represents the group to the loan officer every month. The frequency of meetings among the members was discussed and decided among the members. The average is about once a month. The amount borrowed was larger for individual loans than for group loans. Xac Bank also took collateral, although it did not set strict collateral requirements. The maturity of group loans was slightly shorter than that of individual loans, averaging 192 days. The average maturity of group loans was 192 days, which was slightly shorter than that of individual loans, and the average maturity of group loans was 245 days when the loan size was limited to small loans.

While $66 \%$ of the individuals and $67 \%$ of the group members borrowed for business purposes by purchasing livestock, tools and machinery, the rest used the money for household expenses. For borrowers who took out second or more loans, $52 \%$ of individuals and $43 \%$ of group members borrowed for business purposes. In the case of second and subsequent loans, $52 \%$ of individuals and $43 \%$ of groups borrowed for business purposes. 
Loan briefings were organized by a non-profit organization, the Mongolian Women's Federation (MWF), and out of 40 villages, 15 were assigned to group loans, 15 to individual loans, and 10 to control groups. Groups consisted of 7 to 15 members, and loans were made to individuals on the list of the poor who had about 1 million MNT at the time of participation and whose monthly income was less than 200,000 MNT. In the 19 months since March 2008, the average household has earned only MNT1,100,000. Livestock ownership was also taken into account in the selection of the target population. In 15 villages, groups were formed, leaders were elected, group rules were signed, and members lived in the same village and knew each other.

There is no significant difference in poverty levels between the group lending and individual lending groups, and we find similarities in household composition, employment and consumption patterns, and asset size. The majority of borrowing households had at least one loan at the time of the baseline survey.

\section{Means of the Increasing and Decreasing Groups after the Introduction of MF}

In this section, we compare the baseline survey before the introduction of microfinance and the follow-up survey after the introduction of MF for each variable. Two income variables, household income and business income are treated as income variables, and a default variable is used as the repayment rate. Figure 1 shows the mean values of the six variables for households that increased in the follow-up survey relative to the baseline survey. Figure 1 shows the mean values for households where the six variables increased in the follow-up survey compared to the baseline survey, and Figure 2 shows the mean values for households where they decreased. Seven variables are examined: male dummy, age, education level, total borrowing, number of household members, amount of collateral, and length of the loan. In Figure 1, the average of the households that increased, the default is significantly higher for Male. It can be seen that the more male the household, the higher the Default. The income and expenditure variables are small. In other words, it is women who have risen. Default is high for all variables except Borrowing Period and Collateral. Education, which indicates the level of education, also defaults to a higher level. In Age, business income and business expenditure increase with younger age, and expenditure items of household consumption and household food consumption increase with older age. In Education, income and expenditure succeed at the same level. Total borrowing, total loan, increases the income variable and business expenditure; compared to the average of failed households, which decreased after MF, it can be confirmed that borrowing to some extent increases income. HH size, the number of household members, increases expenditure as expected when it increases. Moreover, income does not increase relative to expenditure. The larger the collateral, the higher the income and expenditure. For the term of the loan, both expenditure and income are about the same. For business income to increase, the two figures show that younger age, a female, a larger amount of collateral and a smaller number of household members are more likely to increase business income. It is also possible to assume that a certain amount of borrowing is better. 


\section{Increased: mean in difference}
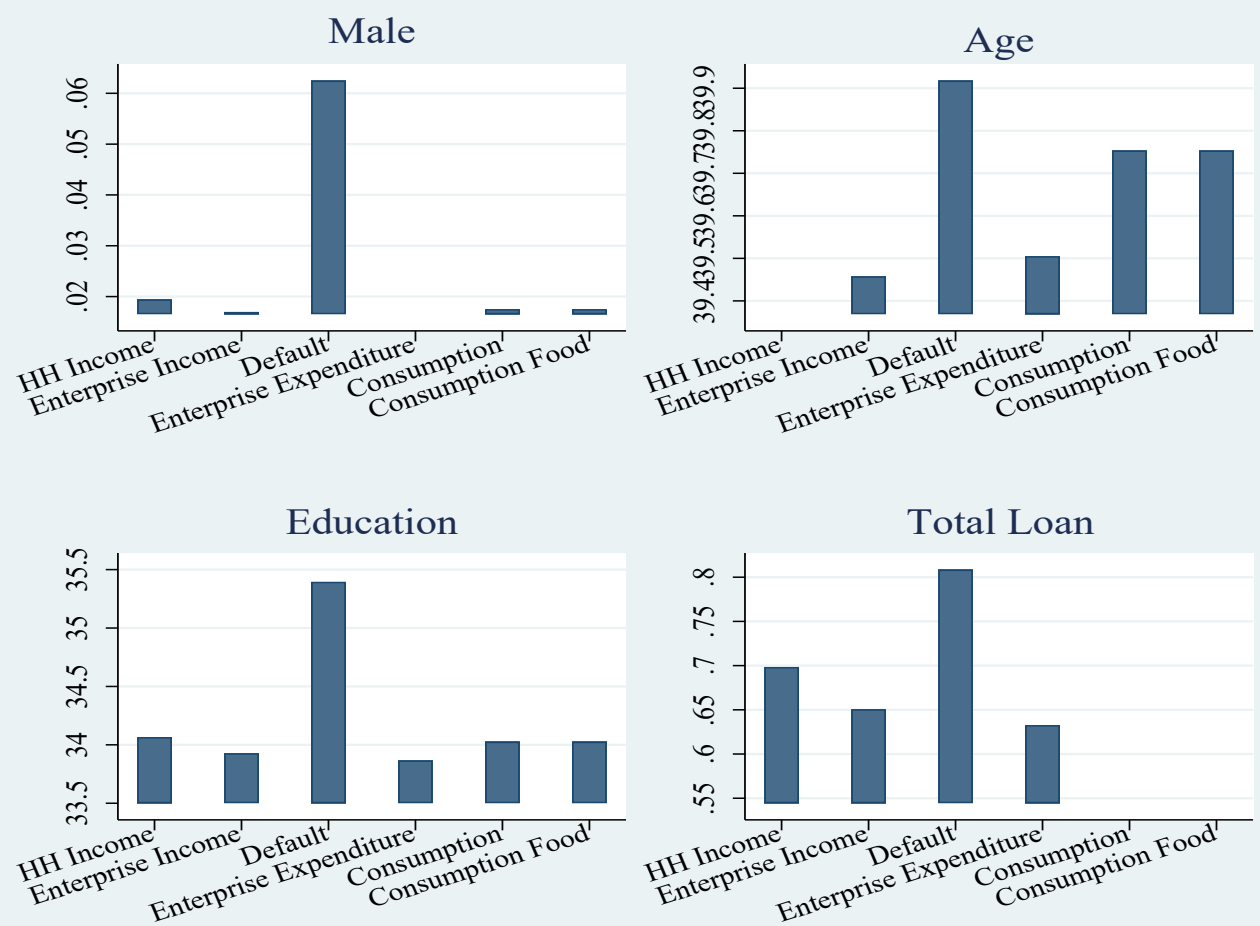

HH Size
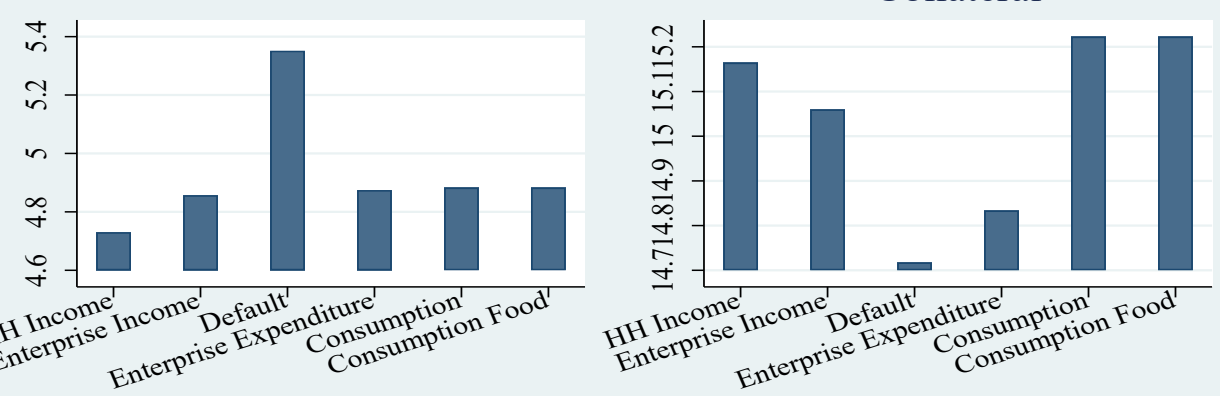

\section{Borrowing Period}

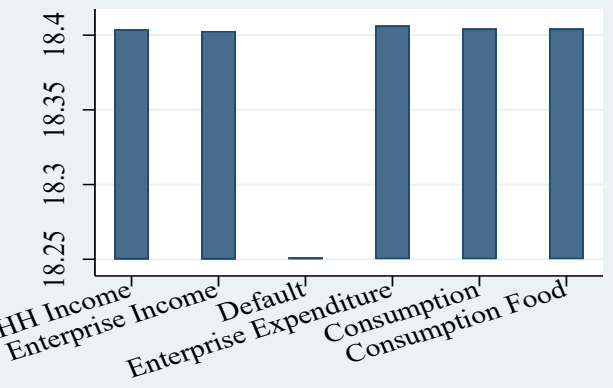

Figure 1. Average of households with increases in income, expenditure and default 


\section{Reduced: mean in difference}

Male

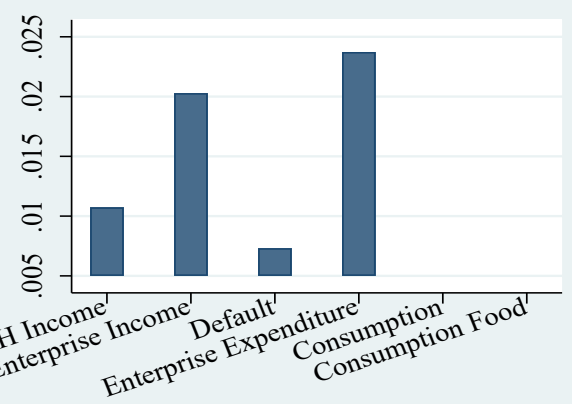

Education

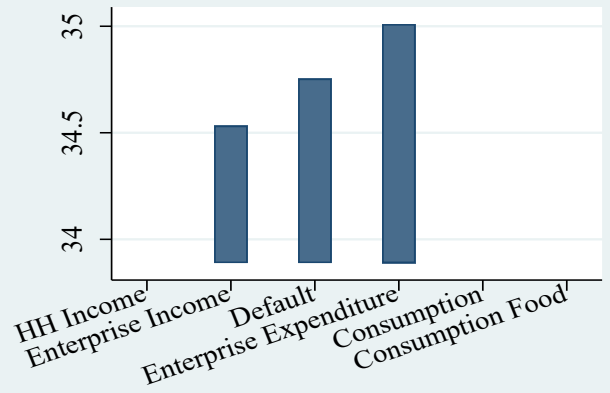

HH Size

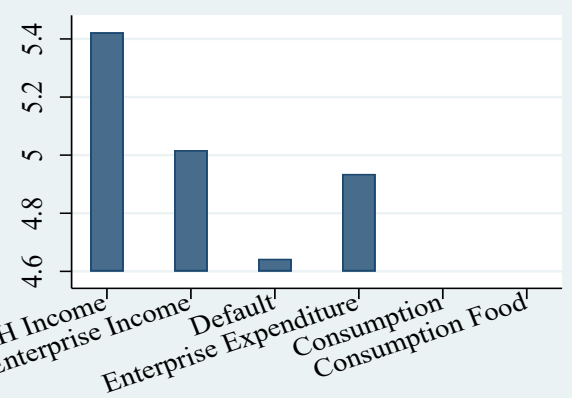

\section{Borrowing Period}

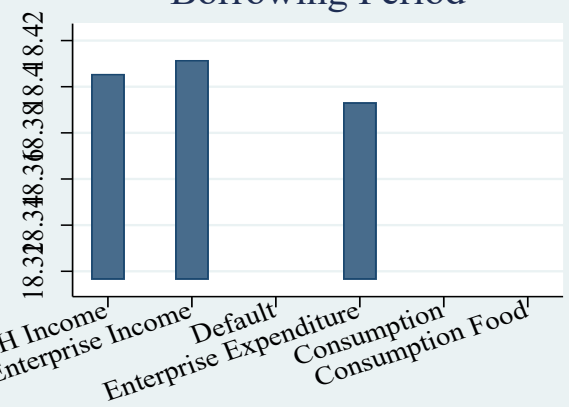

Age

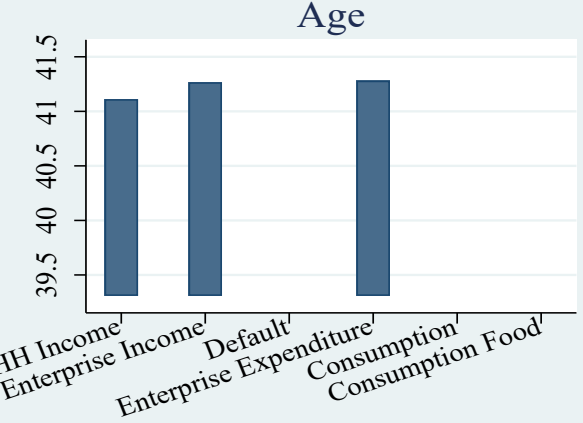

Total Loan

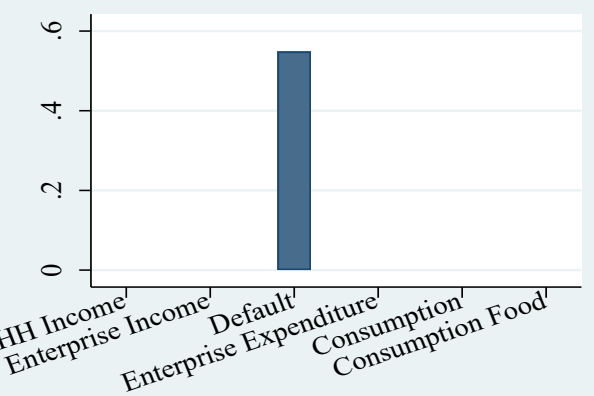

Collateral

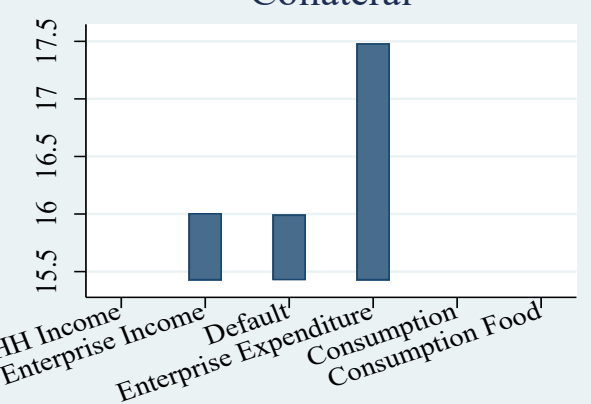

Figure 2. Average of households with a decrease in income, expenditure and default 


\section{Estimation Results}

\subsection{Mean Intervention Effect}

In this section, we estimate the average intervention effect using ATE, which includes the variables used in the previous section as explanatory variables: household income, Enterprise Income (business income), default on borrowing, household consumption, and food consumption among household consumption. We estimated We also measured ATE for three different types of microfinance: individual and group lending, and the sum of individual and group lending.

Figure 3 shows that household income has decreased for all types of microfinance, but it has decreased particularly for individual lending relative to the control group. Business income has risen the most for personal lending relative to the control group. Microfinance borrowing has led to an increase in business income, but not in household income. Defaults are higher for group lending. In terms of expenditure items, individual lending has a higher effect on both total consumption and food consumption than the control group. Group lending is more effective than individual lending in controlling expenditure 。

\section{Average Treatment Effect}
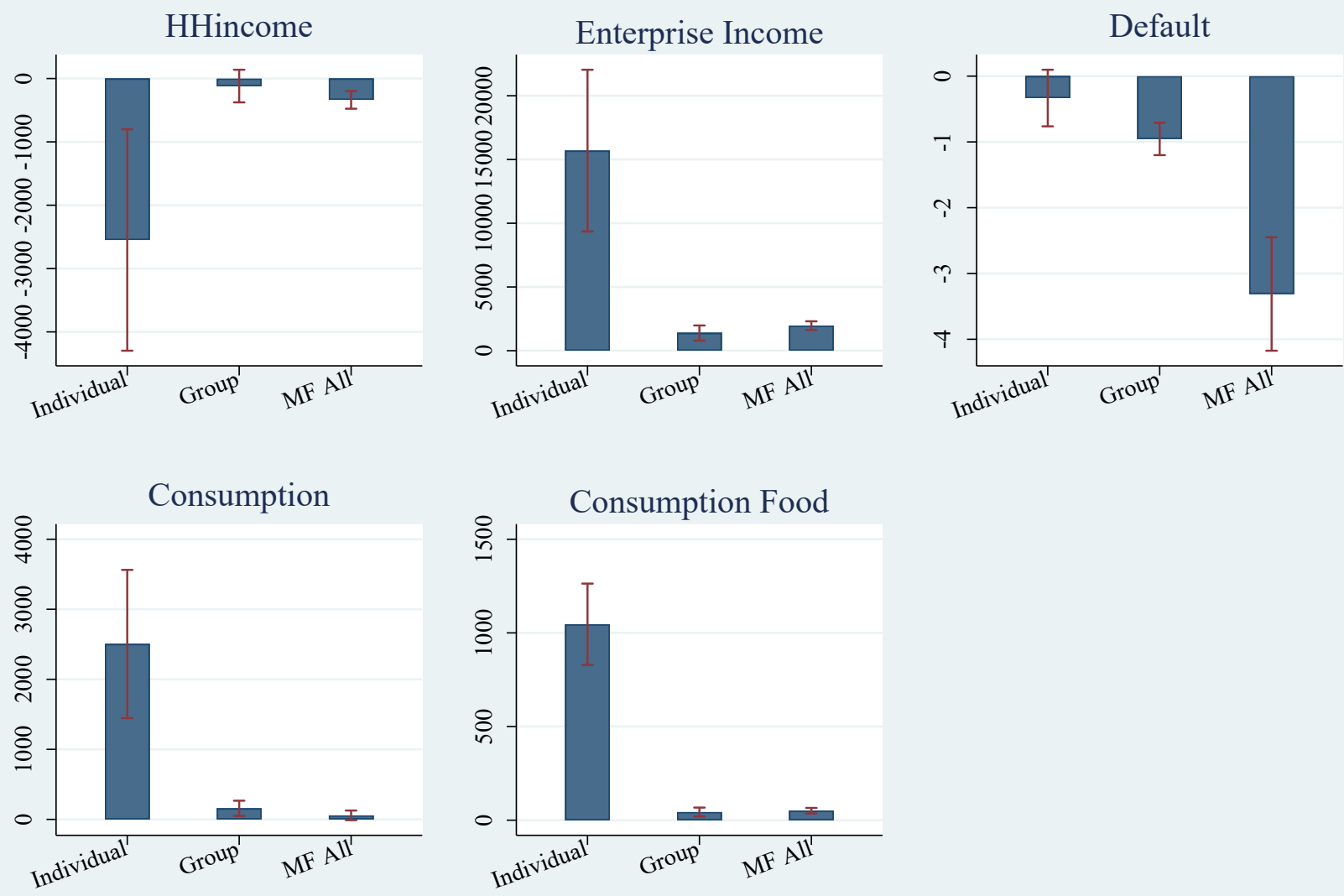

Figure 3. MF ATE of income, expenditure and default by type 


\subsection{Estimating the Conditional Mean Intervention Effect}

Suppose that the individual intervention effects for all individuals are distributed around the average intervention effect, regardless of whether they has high eucation they are or not, whether they are self-employed or not, and how many family members they have. In this case, it would mean that for almost all individuals, the group lending intervention would be expected to have a positive effect for self-employed, and number of family members, but not otherwise.

In real-world intervention studies, it is not possible to observe outcomes for subjects who received a particular intervention, if they did not receive the intervention or if they received some other intervention.

Therefore, in order to test which explanation is more plausible, we used machine learning methods to estimate the effect of the intervention on each respondent and obtain counterfactuals. Here, we estimated the conditional intervention effect (CATE) using the causal forest (CF) proposed by Wager and Athey (2018), and obtained the predicted value of the CATE for each respondent using their individual demographic information.

In the line graphs in Figure 4, the horizontal axis is the variable and the vertical axis is the mean and standard error of the causal forest estimates.

The left-hand side of the first column shows the effect of each variable on household income and the difference between group and individual lending. age and education, NumOfLoans. The left column shows the effect of each variable on household income. Only in the case of the borrowing period and collateral is the value of private lending smaller. In particular, there is a large difference between age, HHsize and collateral. This means that the older the age, the larger the number of household members, and the smaller the amount of collateral, the more desirable the type of individual microfinance is than group lending.

On the right of the first column is business expenditure: for all variables except for MALE and TOTAL LOAN, the impact on business income is different for individual and group lending. The impact on business income differs between individual and group lending for all variables except for market and total loans, where the impact on business income is particularly large for enterprise, the number of sole traders at the time of borrowing. Of the variables that differ between types of microfinance, only HHsize is higher for group lending. Business income is also found to have a greater effect on many variables for individual lending. Individual lending is also used for those who have a private business before borrowing, and in particular, a smaller amount of loans increases business income. The higher the age of the household, the higher the number of loans, and the larger the number of private businesses, the higher the business expenditure.

The second column, on the left, shows business income, which has almost the same shape as business expenditure. The magnitude of business expenditure is related to the magnitude of business income, and the effect of group and individual lending is also almost identical. 
The second column on the right shows the presence or absence of default. We find no difference in default for almost all variables. Default does not make a difference for almost all variables. However, it is confirmed that the larger the total amount borrowed, the less defaulted the longer the loan term, and the less defaulted the fewer the number of loans. The results are the same for the whole sample, but with the expected sign.
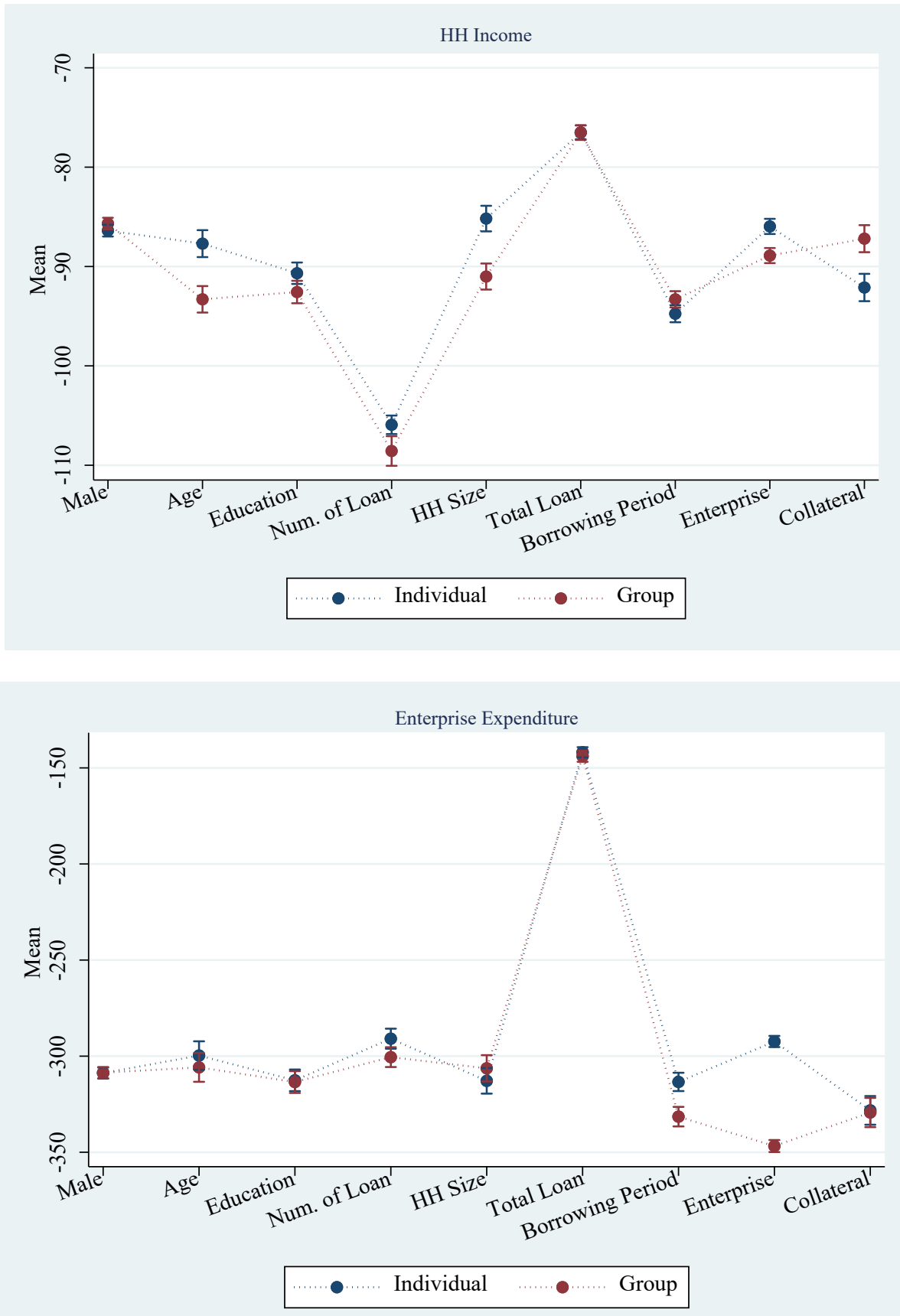

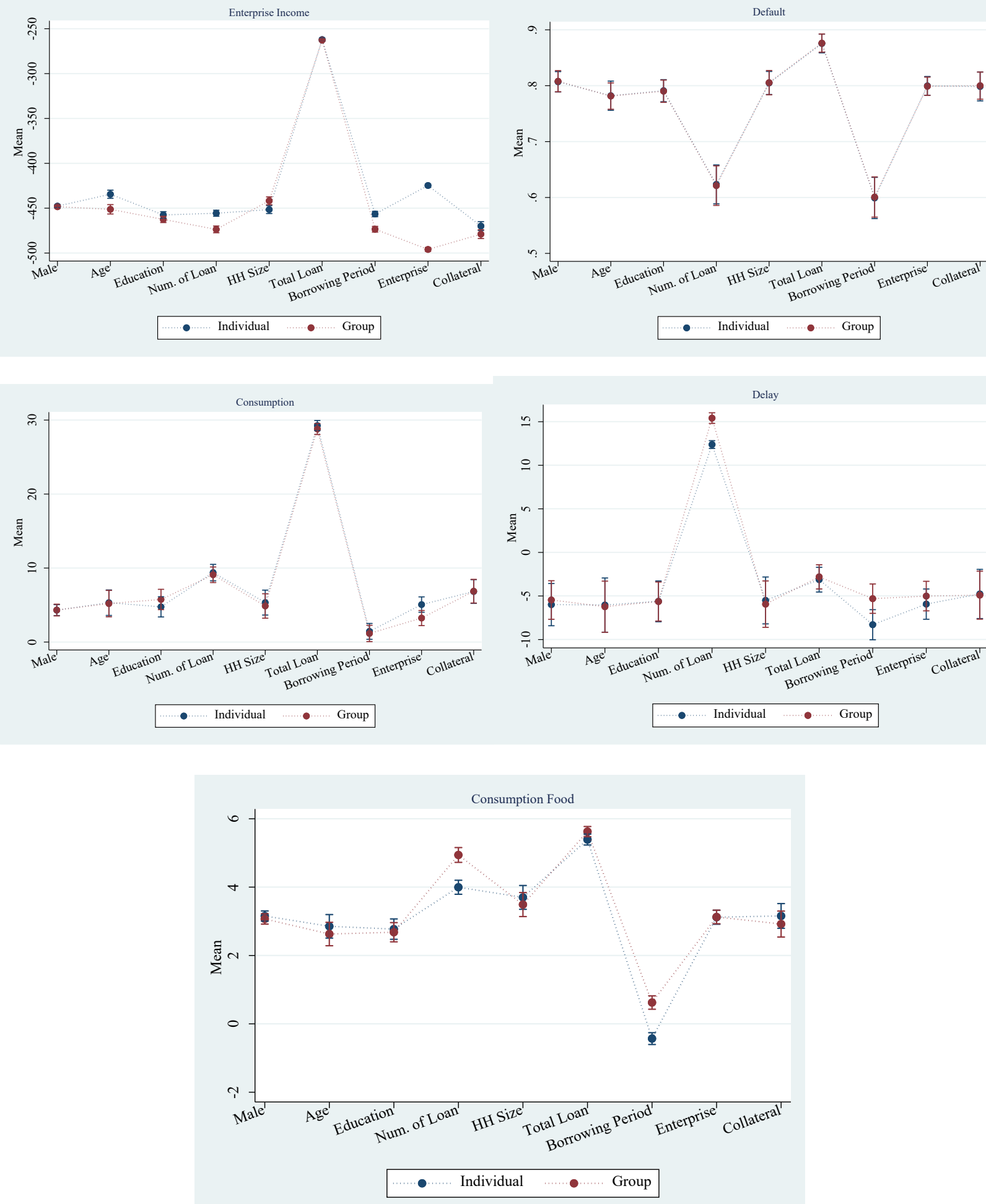

Figure 4. Estimates of CF by MF type 
On the left of the third column are the dates of late repayment. The number of loans and the duration of loans have different effects on the type of microfinance. Group lending tends to be repaid more quickly, and individual lending tends to be repaid more slowly as the duration of the loan increases. The right-hand side of the third column shows household consumption. The fourth column shows household food consumption. When we restrict the analysis to household food consumption, only the number of loans and the duration of loans differ by type of microfinance. Group lending tends to increase food consumption. The higher the number of loans, the more likely it is that group lending will be used for food consumption. The fact that group lending increases food consumption more for households that borrow more than once and for borrowers with longer borrowing periods indicates that there are households that want to increase food consumption by making group members bear the burden of borrowing. We can assume the existence of the moral hazard.

5.3 Comparison of Individual Intervention Effects between the Poor within Borrowers and the Whole Sample

In what follows, Figure 5 is constructed from the Causal Forest estimates using data only for households below the median. By comparing Figure 5 for the below-median sample with Figure 4 using the full sample, we can check whether the poorest of microfinance borrowers have similar characteristics. We find that the effect of each variable on household income differs between the group and individual lending. We find heterogeneity in age, NumOfloans, and borrowing period. Only the borrowing period is smaller for individual lending. While we find more heterogeneity across variables in the whole sample, only age and borrowing period are found to affect household income across types of microfinance for the below-median poor. Microfinance in Mongolia can be divided into the poorest and poorest households. The older the age, the more personal lending should be implemented; the shorter the borrowing period, the more personal lending should be implemented; on the right of the first column is business income. For all variables, the impact on business income is different for individual and group lending. For all variables, the impact on business income is different for individual and group lending, especially for enterprise, which is the number of private businesses at the time of borrowing. Among the variables that differ between types of microfinance, the variables market, HHsize and total loan are higher for group lending. Households with below median business income show a different trend from the full sample. For households with more members and more loans, group lending increases business income more than group lending. Individual lending is also more desirable for those who had a private business before borrowing. Business expenditure, analysed only for households below the median business expenditure, has almost the same shape as business income, but in particular, the size of the number of loans has an impact on business expenditure. This confirms that borrowing is used for business purposes. Although microfinance is often used for consumption in the short term and investment in the long term, the same tendency of spending against income through borrowing is confirmed in the whole sample. 

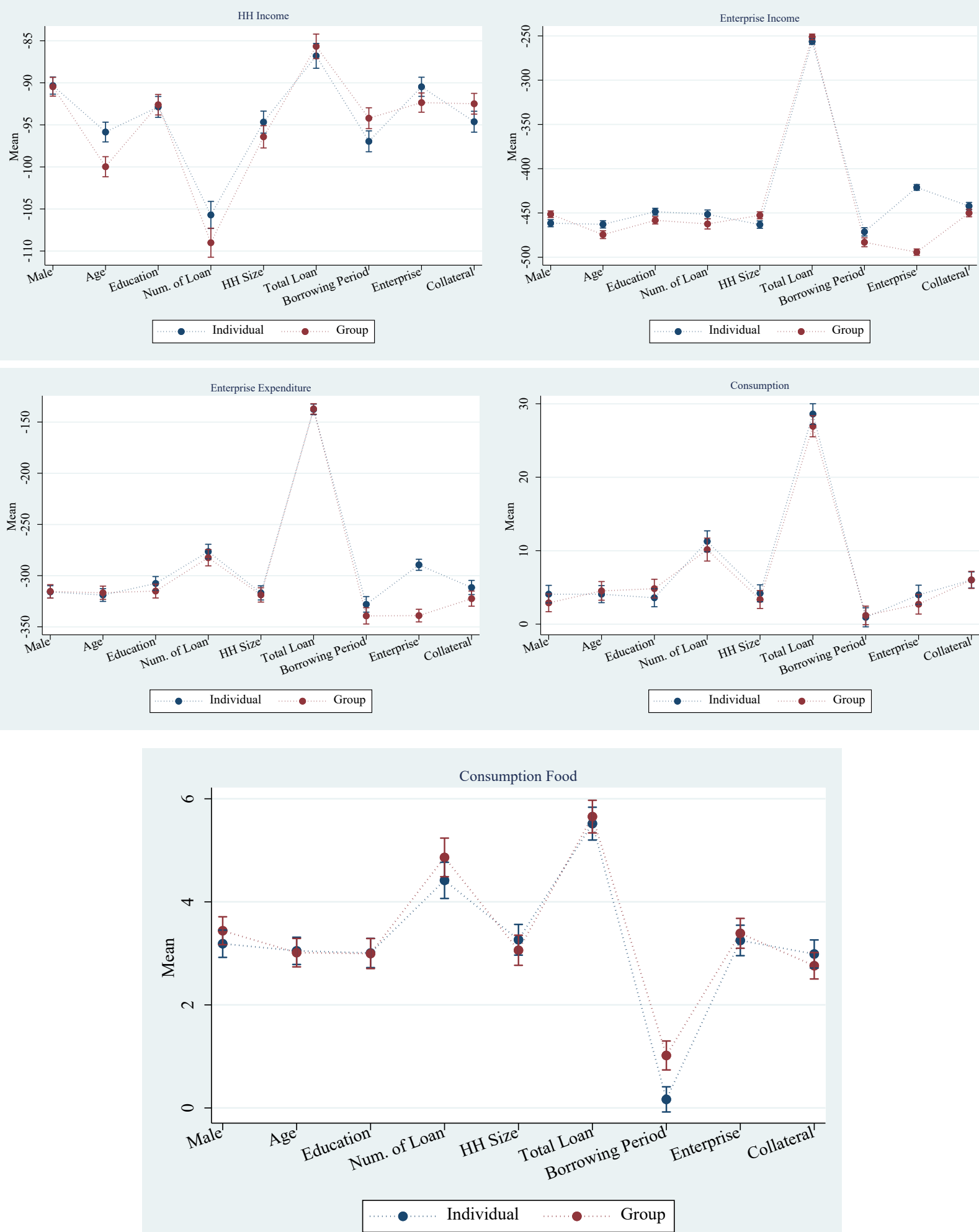

Figure 5. Estimates of CF for below median borrowers only 
We could not find any differences in household consumption except for the number of private businesses. In the sample below the median household consumption, no differences could be identified for most variables. The fact that the larger the total amount borrowed, the larger the amount consumed is also the same as in the full sample. The impact on household consumption tends to be the same for both the full sample and the sample below the median. In terms of household food consumption, only the duration of the loan has a different effect for different types of microfinance. Longer borrowing periods reduce food consumption, which is consistent with the results of previous studies. Group lending tends to increase food consumption with longer borrowing periods.

\section{Conclusion}

This study examines the heterogeneity with respect to the effects of the joint and several liability systems of microfinance in Mongolia. The heterogeneity was examined from three perspectives: consumption, repayment rate, and income.

We compared the mean values of each variable for households that increased and decreased household income, business income, default, business expenditure, household consumption and household food consumption. Males increased household income more than females, and the average number of successful households was 4.7, while the average number of unsuccessful households was 5.4, indicating that households with five or fewer members were successful. In terms of consumption, borrowers increased both general consumption and food consumption; business income increased for those aged 40 and under, but decreased for those aged 40 and over. The higher the years of education, the lower the business income.

We then measured the average intervention effect, the ATE, for each type of microfinance, and then estimated heterogeneity using Causal Forest to measure the individual intervention effect. For household income, older age, a larger number of household members, and smaller collateral amount, individual lending type of microfinance is preferred over group lending. Concerning business income and business expenditure, the older the household, the larger the number of loans, and the more private businesses the household owns, the more business expenditure can be increased. On repayment rates, the larger the total amount borrowed, the more likely the household is to default; the longer the term of the loan, the less likely the household is to default; and the fewer the number of loans, the less likely the household is to default. Regarding the delay date, the number of loans and the duration of loans have different effects depending on the type of microfinance. Group lending tends to be repaid more quickly, and individual lending tends to be repaid more slowly the longer the borrowing period. The higher the number of loans, the longer the delay. For household consumption, there is no difference between group and individual lending except for the number of private businesses, but when we restrict the analysis to food consumption, group lending increases food consumption more for households that borrow more than once and for borrowers with longer borrowing periods.

Although we found more variable heterogeneity in the whole sample, we checked whether we 
could obtain the same results for the poorest borrowers with below-median household incomes. We found differences in the post-borrowing effects when comparing the poorest borrowers with the borrowers as a whole. Age and duration of borrowing were found to affect household income for different types of microfinance. The older the age, the more individual lending and the shorter the borrowing period, the more individual lending should be implemented. For households with business income below the median, group lending increases business income more for households with more members and more borrowing.

While previous studies have focused on whether the presence or absence of a joint and several liability systems affected the effectiveness of MF, the results of this study suggest that even if there was no significant difference in each attribute between the treatment and control groups, joint and several liabilities may or may not be effective depending on the level of the attribute. In order to maximize the effect of a simple measure, it is important to understand the factors that affect heterogeneity and the effective level of the heterogeneity. Even if a measure is not effective as a result of RCT, it may become effective if the level of the attribute changes.

\section{References}

Athey, S., \& Imbens, G. W. (2016). Recursive partitioning for heterogeneous causal Effects. Proceedings of the National Academy of Sciences, 113(27), 7353-7360. https://doi.org/10.1073/pnas.1510489113

Athey, S., \& Imbens, G. W. (2019). Machine learning methods that economists should know about. Annual Review of Economics, 11, 685-725. https://doi.org/10.1146/annurev-economics-080217-053433

Athey, S., Tibshirani, J., \& Wager, S. (2019). Generalized random forests. The Annals of Statistics, 47(2), 1148-1178. https://doi.org/10.1214/18-AOS1709

Bertrand, M., Crépon, B., Marguerie, A., \& Premand, P. (2017). Contemporaneous and PostProgram Impacts of a Public Works Program: Evidence from Côte d'Ivoire. World Bank. http://hdl.handle.net/10986/28460

Breiman, L., Friedman, J., Stone, C. J., \& Olshen, R. A. (1984). Classification And Regression Trees. CRC press.

Carter, M. R., Tjernström, E., \& Toledo, P. (2019). Heterogeneous impact dynamics of a rural business development program in Nicaragua. Journal of Development Economics, 138, 77-98. https://doi.org/10.1016/j.jdeveco.2018.11.006

Carpena, F., Cole, S., Shapiro, J., \& Zia, B. (2013). Liability structure in small-scale finance: evidence from a natural experiment. The World Bank Economic Review, 27(3), 437-469. https://doi.org/10.1093/wber/lhs031

Chowdhury, P. R. (2005). Group-lending: Sequential financing, lender monitoring and joint liability. Journal of development Economics, 77(2), 415-439. https://doi.org/10.1016/j.jdeveco.2004.05.005 
Chernozhukov, V., Demirer, M., Duflo, E., \& Fernandez-Val, I. (2018). Generic machine learning inference on heterogeneous treatment effects in randomized experiments, with an application to immunization in India (No. w24678). National Bureau of Economic Research. https://doi.org/10.3386/w24678

Davis, J. M., \& Heller, S. B. (2020). Rethinking the benefits of youth employment programs: The heterogeneous effects of summer jobs. Review of Economics and Statistics, 102(4), 664-677. https://doi.org/10.3386/w23443

De Neve, J. E., Imbert, C., Spinnewijn, J., Tsankova, T., \& Luts, M. (2019). How to Improve Tax Compliance?: Evidence Frompopulation-wide Experiments in Belgium. University of Warwick, Centre for Competitive Advantage in the Global Economy, Department of Economics.

Farbmacher, H., Kögel, H., \& Spindler, M. (2019). Heterogeneous Effects of Poverty on Cognition. https://doi.org/10.1016/j.labeco.2021.102028

Fischer, G. (2013). Contract structure, risk-sharing, and investment choice. Econometrica, 81(3), 883-939. https://doi.org/10.3982/ECTA9100

Giné, X., Jakiela, P., Karlan, D., \& Morduch, J. (2010). Microfinance games. American Economic Journal: Applied Economics, 2(3), 60-95. https://doi.org/10.1257/app.2.3.60

Giné, X., \& Karlan, D. S. (2014). Group versus individual liability: Short and long term evidence from Philippine microcredit lending groups. Journal of development Economics, 107, 65-83. https://doi.org/10.1016/j.jdeveco.2013.11.003

Hoffman, I., \& Mast, E. (2019). Heterogeneity in the effect of federal spending on local crime: Evidence from causal forests. Regional Science and Urban Economics, 78, 103463. https://doi.org/10.1016/j.regsciurbeco.2019.103463

Knittel, C. R., \& Stolper, S. (2019). Using machine learning to target treatment: The case of household energy use (No. w26531). National Bureau of Economic Research. https://doi.org/10.3386/w26531

Miller, S. (2020). Causal forest estimation of heterogeneous and time-varying environmental policy effects. Journal of Environmental Economics and Management, 103, 102337. https://doi.org/10.1016/j.jeem.2020.102337

O'Neill, E., \& Weeks, M. (2018). Causal tree estimation of heterogeneous household response to time-of-use electricity pricing schemes. arXiv preprint arXiv:1810.09179. https://doi.org/10.17863/CAM.33793

Attanasio, O., Augsburg, B., De Haas, R., Fitzsimons, E., \& Harmgart, H. (2015). The impacts of microfinance: Evidence from joint-liability lending in Mongolia. American Economic Journal: Applied Economics, 7(1), 90-122. https://doi.org/10.1257/app.20130489

Attanasio, O., Augsburg, B., De Haas, R., Fitzsimons, E., \& Harmgart, H. (2015). The impacts of microfinance: Evidence from joint-liability lending in Mongolia. American Economic Journal: Applied Economics, 7(1), 90-122.

Tibshirani, J., Athey, S., Friedberg, R., Hadad, V., Hirshberg, D., Miner, L., ... \& Tibshirani, M. J. 
(2018). Package 'grf'.

Wager, S., \& Athey, S. (2018). Estimation and inference of heterogeneous treatment effects using random forests. Journal of the American Statistical Association, 113(523), 1228-1242. https://doi.org/10.1080/01621459.2017.1319839

Zhao, Z., \& Harinen, T. (2019, October). Uplift modeling for multiple treatments with cost optimization. In 2019 IEEE International Conference on Data Science and Advanced Analytics (DSAA) (pp. 422-431). IEEE. https://doi.org/10.1109/DSAA.2019.00057

\section{Copyrights}

Copyright for this article is retained by the author(s), with first publication rights granted to the journal.

This is an open-access article distributed under the terms and conditions of the Creative Commons Attribution license (http://creativecommons.org/licenses/by/4.0/) 